\title{
AdVANCES IN SEA-ICE ReSEARCH BASED oN ReMotely SENSED PASSIVE MicRowaVe DATA
}

By R.G. Barry, J. Maslanik, K. Steffen, R.L. Weaver, V. Troisi, D.J. Cavalieri, and S. Martin

$\mathrm{S}$ the polar ocean environment. Annual cycles of sea-ice cover and their interannual variations contribute significantly to changes in surface reflectivity and turbulent heat fluxes from the Earth's surface that affect high-latitude climate sensitivity. Polar sea ice also influences the deepwater formation in the world ocean. We know little about sea-ice conditions before the late nineteenth century. Consistent weekly mapping of ice extent in the Arctic seas dates from the early 1950 s and for the Antarctic from the 1970s. Moreover, the fractional coverage (or concentration) of sea ice in the interiors of the polar packs was largely unknown until the advent of polar-orbiting satellites.

In the polar regions, records for meteorological and oceanographic data are short, and the observations are poorly distributed geographically. For example, the Arctic Basin and Antarctic Ocean have less than 30 long-term surface-reporting stations to cover areas in each hemisphere equivalent to the size of the contiguous United States. Although coordinated exploration began in the late nineteenth century during the First International Polar Year, 1882-1883, virtually all continuously operating stations in the North American Arctic date from $\sim 1950$ and in the Antarctic from the International Geophysical Year in 1957. Given the sparse data base and short-duration records available, environmental research in the polar regions must rely heavily on remotely sensed data and on information compiled over short periods from single-site projects and expeditions.

Over the past 2 decades, remote sensing by satellite has played an increasingly important role in

R.G. Barry, J. Maslanik, K. Steffen, R.L. Weaver, V. Troisi University of Colorado Boulder, CIRES/NSIDC Campus Box 449 Boulder, CO 80309, USA. D.J. Cavalieri, NASA Goddard Space Flight Center (code 971), Greenbelt, MD 20771, USA. S. Martin, School of Oceanography WB-10, University of Washington, Seattle, WA 98195 , USA. monitoring of the polar environment. Sensors used in these studies include those operating in the visible/infrared and the microwave. However, for monitoring surface conditions, the utility of visible and infrared sensors on satellite systems such as the National Oceanic and Atmospheric Administration (NOAA) Advanced Very High Resolution Radiometer (AVHRR), Defense Meteorological Satellite Program (DMSP) Operational Line-Scan System (OLS), Landsat, and Systeme Probatoiré d'Observation de la Terre (SPOT) is limited by persistent cloud cover over the polar oceans and, in the case of visible and reflected near-infrared radiation, by low solar illumination during much of the year. A major advantage of using microwave radiometry is that microwave surveillance is not hampered by cloud cover or polar darkness.

This paper surveys the unique contributions that have been made to our knowledge of polar sea ice since the early 1970 s by passive microwave remote sensing. The combination of all-weather capability and the absence of any dependence of microwave emission on solar radiation, yields data particularly suited to polar applications. The interested reader will find an extensive treatment of the microwave remote sensing of sea ice in a newly published book by Carsey (1993).

\section{Passive Microwave Remote Sensing}

The guiding principle in the application of passive microwave sensors is that in the frequency range 9 to 90 GigaHertz $(\mathrm{GHz})$, there are three atmospheric windows that permit detection of the natural black-body radiation emitted by the surface. These are bounded by absorption lines due to water vapor near $22.2 \mathrm{GHz}$ and oxygen near 60 and $118.8 \mathrm{GHz}$ (Waters, 1976; Chahine et al., 1983). For atmospheric moisture contents typical in higher latitudes. the atmosphere is relatively transparent at passive microwave frequencies below $40 \mathrm{GHz}$, with the exception of the water-vapor absorption band at $22.2 \mathrm{GHz}$. Polar surfaces can 
therefore be observed under virtually all conditions. The largest variations in the passive microwave signal are attributable to surface characteristics that change the emissivity, as well as to the actual physical temperature. The microwave radiation that is emitted by a surface is expressed as a brightness temperature, $T_{B}$ (in Kelvin), $T_{B}$ $=\mathrm{eT}$. where $\mathrm{T}$ is the mean physical temperature of the snow or ice slab from which the radiation emanates and $\mathrm{e}$ is the emissivity.

The ability of passive microwave radiometers to map sea-ice extent and concentration (i.e., the areal mix of ice and open water) results from the large difference in the microwave emissivity between ice-free and ice-covered waters. For example, at a frequency of $19.35 \mathrm{GHz}$ for nadir view and horizontal polarization (where the plane of polarization of the antenna is parallel to the earth's surface) the emissivity of calm sea water is $\sim 0.44$, yielding a brightness temperature of $\sim 120 \mathrm{~K}$, while the corresponding emissivity of first-year sea ice is $\sim 0.92$, giving a brightness temperature as high as $251 \mathrm{~K}$. Typically, the ocean surface has a brightness temperature of $\sim 130 \mathrm{~K}$ at this frequency. In principle, the large contrast in emissivity between sea ice and water should allow the measured microwave radiances of a single frequency and polarization to be used as a sensitive indicator of sea-ice concentration. However, complications arise because other geophysical factors that influence the radiometric brightness of both the sea surface and sea ice. Wind-roughened seas. cloud droplets, and atmospheric water vapor all can increase the observed sea-surface brightness temperature sufficiently to create errors of $\leq 10 \%$ in estimates of ice concentration and extent (Steffen and Schweiger, 1991).

Factors influencing sea-ice emission include the physical temperature of the ice, the age-dependent salinity content of the ice, and the depth and state of its snow cover. During the course of a winter season, ice formed in open water areas grows to $\sim 1.5-2.0-\mathrm{m}$ thickness and loses much of its salt content by the drainage of brine into the surface layer of the ocean. Ice that has survived at least one melt season exhibits greater volume scattering and therefore lower brightness temperature. The scattering is increased at higher frequencies. This frequency dependence enables the brightness temperature observed at different frequencies to be used to estimate the proportions of ice type. Additionally, surface emissivity is polarizationdependent; the emissivity of sea water is substantially less for vertical polarization than horizontal, whereas first-year sea ice has only a small difference between polarizations. Cavalieri et al. (1984) describe how the differences in brightness temperature with frequency and polarization can be used to map ice concentration and type, taking advantage of the dual-polarized, multispectral radiances of the systems in use since 1978. Problems that are still being studied include the effects of snow melt and melt ponds that collect on the ice surface during summer, and the effects of windroughened seas and cloud droplets associated with weather systems, that cause major changes in microwave signatures (Maslanik, 1992). There have also been field studies of ice characteristics in both polar regions (Comiso and Sullivan, 1986) and programs of aircraft overflights (Cavalieri et al., 1991) designed to collect "ground-truth" data to test and validate various theoretical algorithms used to calculate ice extent and concentration (Steffen and Schweiger, 1991).

Data from various passive microwave sensors have been collected more or less continuously since 1973 (see Fig. 1). These data provide a basis for long-term monitoring of sea ice (Gloersen and Campbell, 1988, 1991). Passive microwave sensors were operated on Nimbus-5 and 6 (1972-
. . differences in

brightness temperature

. . can be used to

map ice concentration

and type . . .

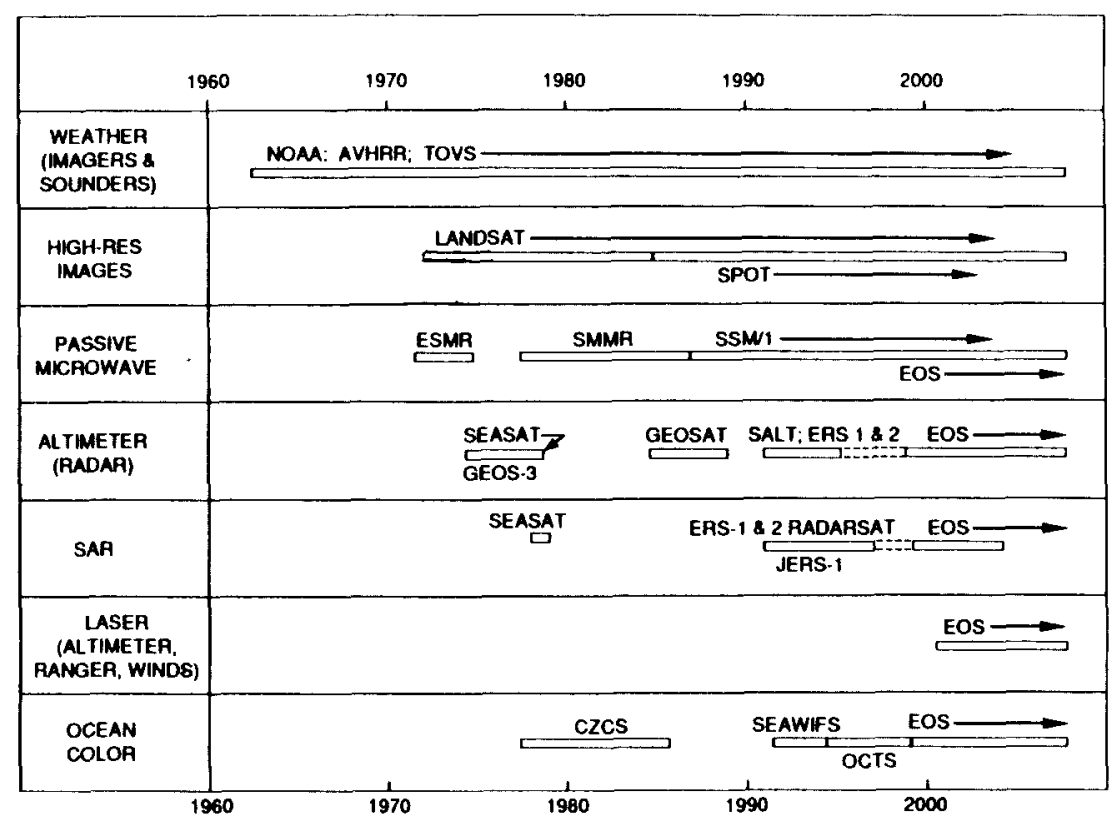

Fig. 1: Past, present and planned satellite missions that can provide data for polar research (from Thomas, 1991). NOAA, National Oceanic and Atmospheric Administration; AVHRR, Advanced Very High Resolution Radiometer; TOVS, TIROS (Television and Infrared Observation Satellite) Operational Vertical Sounder; Landsat, Land Satellite; SPOT, Système Probatoiré d'Observation de la Terre; ESMR, Electrically Scanning Microwave Radiometer; SMMR, Scanning Multichannel Microwave Radiometer; SSM/ I. Special Sensor Microwave Imager; EOS. Earth Observing Systems; Seasat, Sea Satellite; GEOS-3, Geodetic Earth Observation Satellite; GEOSAT, Navy Geodetic Satellite; SALT, Spinsat Altimeter (program discontinued); ERS1\&2, European Remote Sensing Satellite-1\&2; Radarsat, Radar Satellite (Canada); JERS-1, Japanese Earth Resources Satellite 1; CZCS, Coastal Zone Color Scanner; SeaWIFS, Sea Viewing Wide Field of View Sensor; OCTS, Ocean Color and Temperature Sensor. 
1976), Seasat (1978), Nimbus-7 (1978-1987), and since 20 June 1987, DMSP platforms. Early sensors were designed for research and development purposes. The Special Sensor Microwave Imager

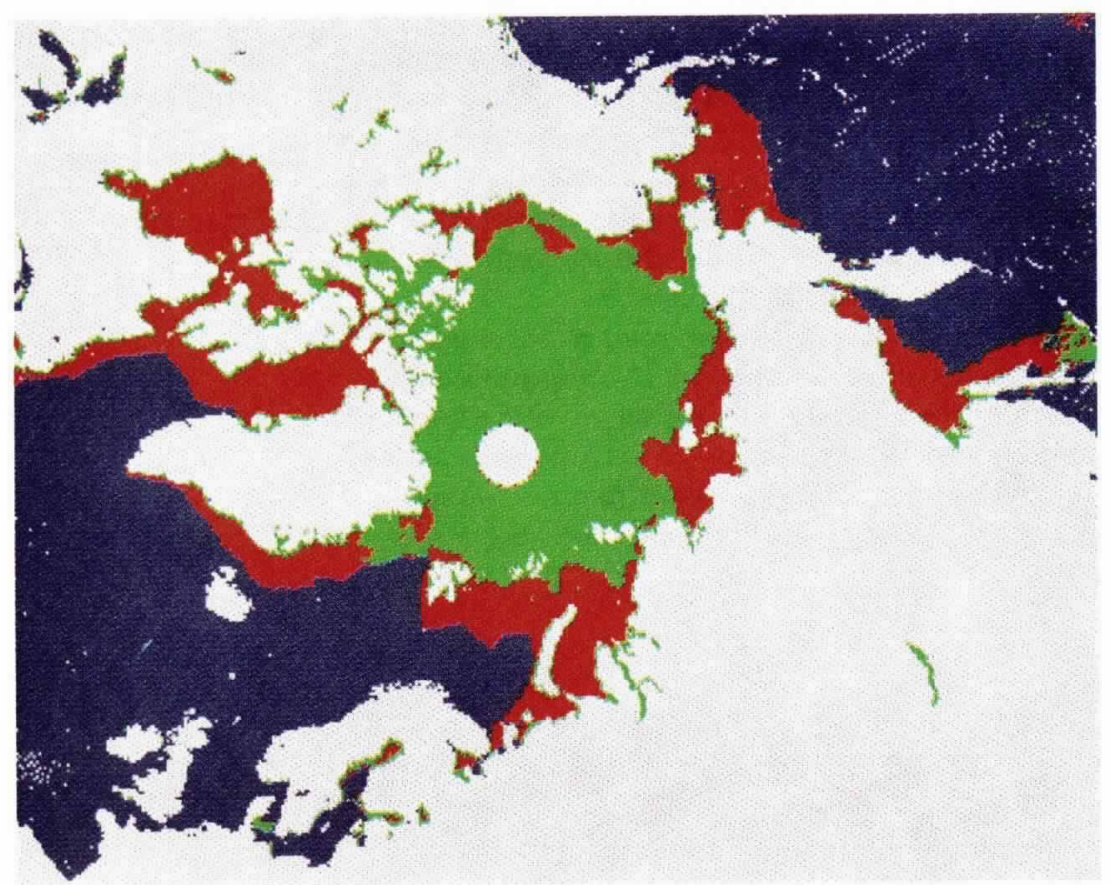

(a)

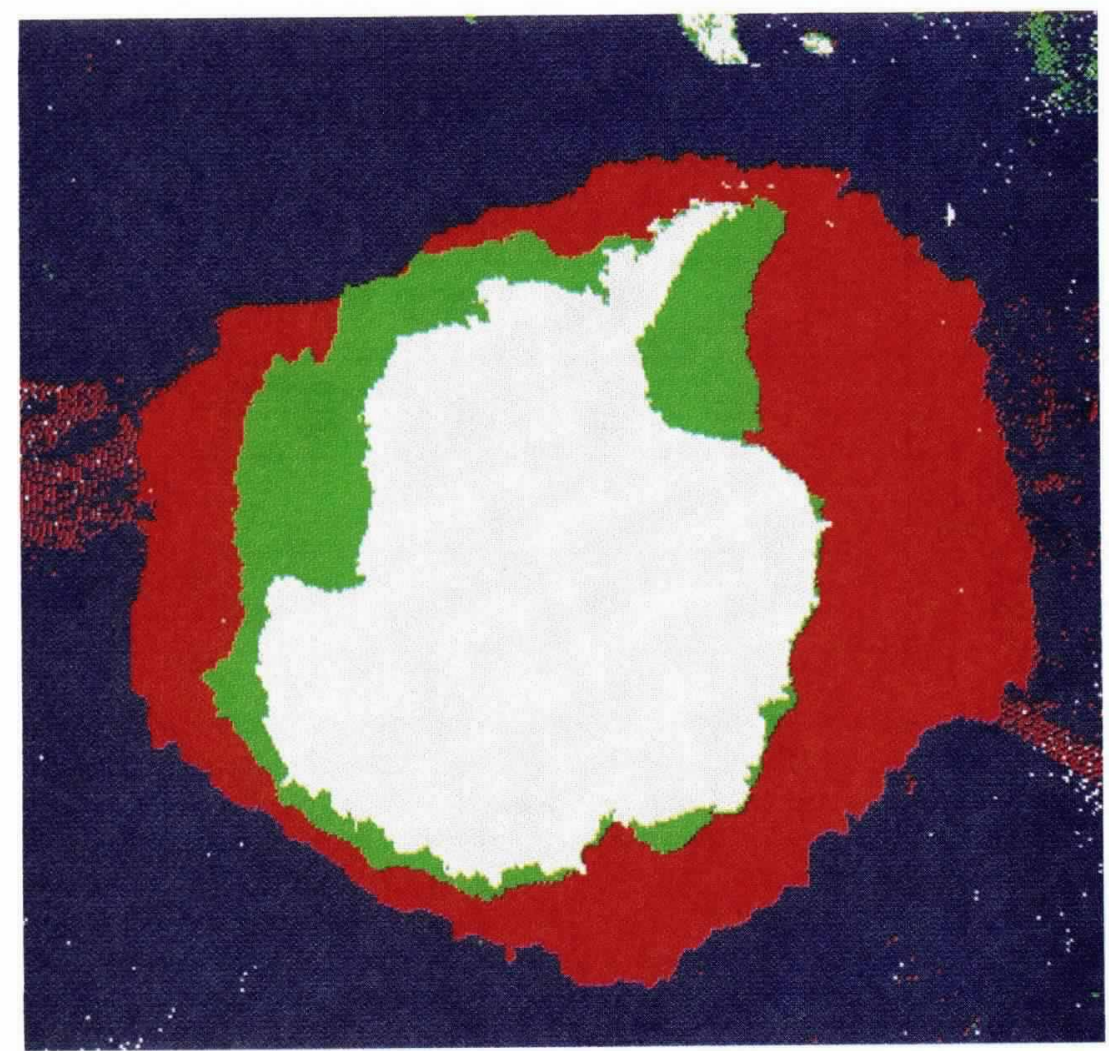

(b)

Fig. 2: Annual maximum (red/blue boundary) and minimum (green/red boundary) polar sea-ice extent from SSM/I data; 3-day averages for the end of March and the end of August, 1988. Some residual weather effects are visible in the Southern Ocean.
(SSM/I) on the DMSP satellites is the first operational passive-microwave sensor.

The first radiometer to provide complete coverage of the polar regions was the Electrically Scanning Microwave Radiometer (ESMR) launched on the Nimbus-5 spacecraft in December 1972. The ESMR was a single-channel radiometer measuring microwave emission at $19.35 \mathrm{GHz}$ with horizontal polarization. The ESMR data have been used to describe seasonal and regional variations in sea-ice extent and concentration in the southern (Zwally et al., 1983) and northern (Parkinson et al., 1987) polar regions. The two major limitations of the ESMR were its inability, as a single-frequency instrument, to distinguish different ice types within the field-of-view of the instrument and its inability to accommodate variations in the physical temperature of the radiating upper ice surface.

In October 1978, a Scanning Multichannel Microwave Radiometer (SMMR) was placed in orbit on both the Seasat and Nimbus-7 satellites. Unfortunately, the active life of Seasat was only 100 days, whereas the Nimbus-7 SMMR continued to provide data until August 1987. The SMMR operated on alternate days and provided 10 channels of measurements, dual-polarized radiances at five frequencies: $6.6,10.7,18,21$, and $37 \mathrm{GHz}$. The 18 and $37 \mathrm{GHz}$ channels are the principal ones used for sea-ice applications. With the SMMR, the potential for overcoming some of the limitations of the single-wavelength ESMR was realized. The multichannel SMMR improved the accuracy of ice-concentration determinations and provided the first satellite observations of multiyear-ice concentration and ice temperature (Cavalieri et al., 1984).

A new generation of multichannel microwave imager was launched on a DMSP F-8 satellite in 1987. DMSP satellites F-10 and F-11 launched 12 December 1990 and 28 November 1991, respectively, both carry SSM/I sensors, but the F10 data are of limited scientific usefulness due to the varying swath width ( 736 to $851 \mathrm{~km}$ ) caused by the noncircular orbit of F-10. The Special Sensor Microwave/Imager (SSM/I) provides seven channels of data: dual-polarized radiances at 19.3, 37 , and $85.5 \mathrm{GHz}$ and single-polarized radiances at $22 \mathrm{GHz}$. The highest spatial resolution $(15 \mathrm{~km})$ is provided by the $85.5 \mathrm{GHz}$ channel, because spatial resolution increases with frequency. However, this channel stopped functioning on F-8 after 1 year. The SSM/I will be flown on subsequent DMSP satellites providing continuous coverage well into the 1990s (Barry, 1991).

\section{Recent Advances}

Major accomplishments of the work completed using passive microwave data include the determination of the spatial-temporal variability of sea ice in both hemispheres and the study of open water areas within the pack. 
Spatial-Temporal Variability in Ice Cover

The combined Nimbus-5 ESMR and Nimbus7 SMMR data sets provide 15 years of almost continuous observations of polar sea ice. The microwave radiances from these sensors have been used to derive quantitative measures of both ice extent and ice concentration for the purpose of defining the seasonal, regional, and interannual variability over the period of record. The largest changes in ice cover follow the annual cycle of ice formation, advection, and melt. In the Northern Hemisphere, ice extent ranges from a minimum of $\sim 8 \times 10^{6} \mathrm{~km}^{2}$ in September to a maximum of $\sim 15 \times 10^{6} \mathrm{~km}^{2}$ in March. In the Southern Hemisphere, ice cover extends as far north as $59^{\circ}$ $S$ and covers an area of $20 \times 10^{6} \mathrm{~km}^{2}$ in September decreasing to a minimum of $\sim 4 \times 10^{6} \mathrm{~km}^{2}$ in February. Figure 2 illustrates the maximum seaice extent in the two polar regions as mapped with SSM/I data. Figure 3 shows the seasonal cycle for the period 1973-1987. This figure shows a much larger ice cover in the Southern Hemisphere winter. There is also an asymmetry in the growth and decay of the ice cover in the Southern Ocean with a gradual increase and more rapid decay, compared with a symmetrical cycle in the northern hemisphere. The interhemispheric differences arise largely because of the different distributions of land and ocean in the two polar regions, with an unconfined ice edge in the Southern Ocean. The asymmetry in the annual cycle in the Antarctic is caused by more rapid melt in summer, which has been attributed to oceanic influences (Gordon, 1981).

For the Arctic, Figure 4 displays the annual mean sea-ice extents derived from both the ESMR and SMMR records for each of the Arctic regions noted above, as well as for the total. Considerable temporal variability in the passive microwave record is apparent for most regions. The regions showing the greatest variability are those with unconfined ice boundaries, in contrast to the Arctic
Ocean and Hudson Bay, which are almost completely ice covered during the winter months.

Regional differences in sea-ice cover have been studied by dividing the polar regions according to the major seas (Zwally et al., 1983; Parkinson et al., 1987). In both hemispheres, large regional variability is observed, and it seems characteristic that the area of sea ice shows short-term fluctuations that are not in phase between regions. On seasonal and synoptic time scales the advance and retreat of the ice cover is strongly influenced by the position of quasi-stationary atmospheric pressure systems (Cavalieri and Parkinson, 1981, 1987). Figure 4 confirms some out-of-phase relationships between various regions noted by earlier workers. For example, during 1973-1976 (the ESMR observation period), the Greenland Sea and the Kara/Barents Seas show an overall negative correlation.

Apart from the large regional variability, there are some decadal trends. For the entire Northern Hemisphere, Figure 4 shows a slight negative trend during 1979-1986 in contrast to a mean positive trend during 1973-1976 (Parkinson and Cavalieri, 1989). An independent analysis with re-worked data finds a small but significant trend of $\sim-2.1$ $\pm 0.9 \%$ in the ice extent of the Arctic during 19781987 (Fig. 5), with a decrease in open-water areas within the pack of $3.5 \pm 2.0 \%$. The ice extent contracted, but the pack became more compact, suggesting that several factors may be operating. However, no significant trend is evident in the Antarctic (Gloersen and Campbell, 1991). These results amplify their earlier finding that the annual maximum ice extents had decreased in both polar oceans, but that the trends have a low level of statistical confidence (Gloersen and Campbell, 1988). In addition to the annual trends, the extent of Arctic and Antarctic ice (Fig. 5) shows considerable interannual variability in both the winter maxima and summer minima. It appears that a 20-to-30-year time series of sea-ice observations

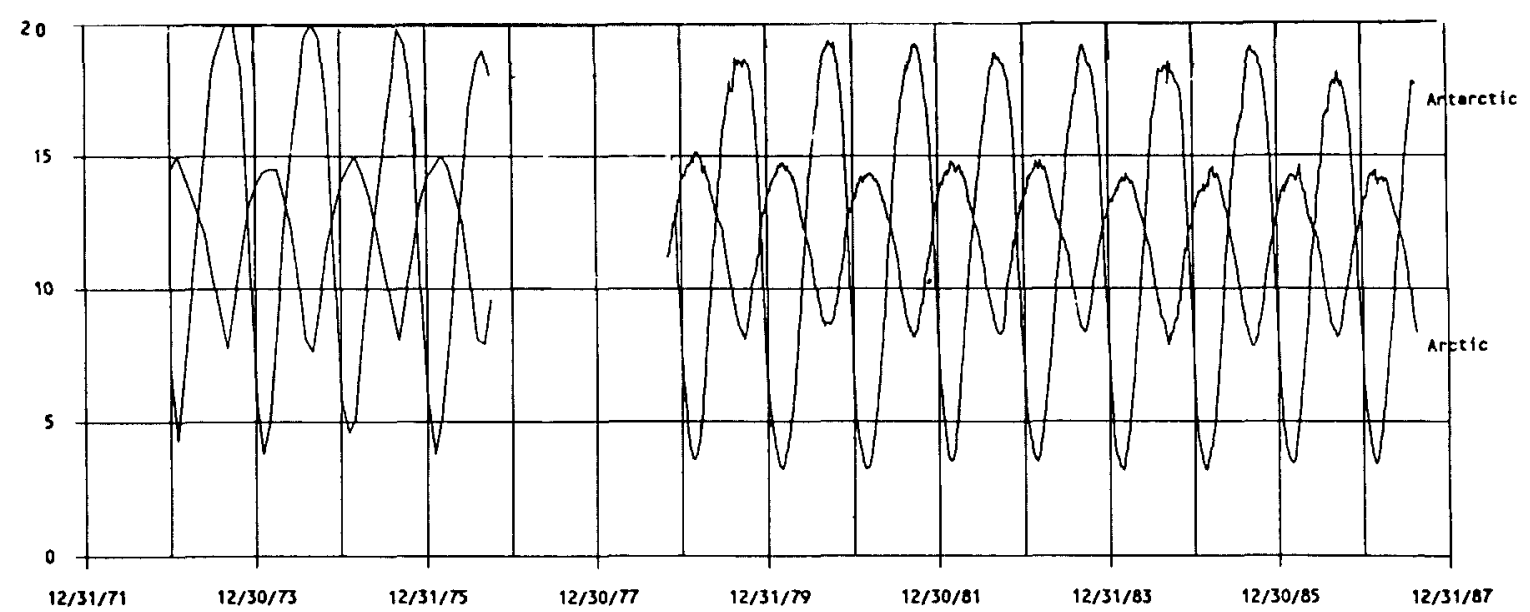

Fig. 3: Combined ESMR and SMMR records of Arctic and Antarctic ice extent (million $\mathrm{km}^{2}$ ). (Modified from Gloersen and Campbell, 1988.) 

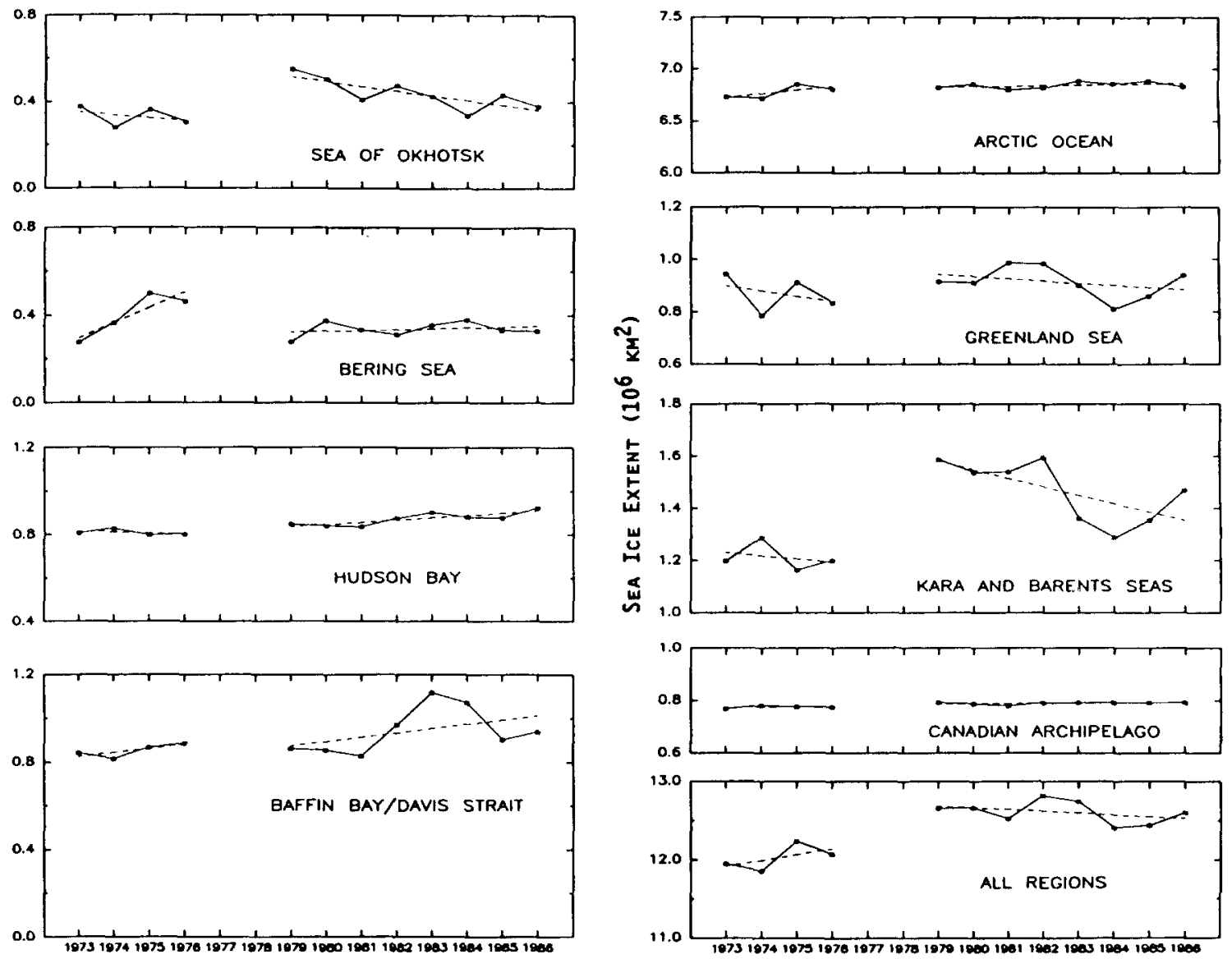

Fig. 4: Annual mean sea-ice extents for 8 Arctic regions and for the sum. The 2 dashed lines in each plot indicate the least squares fits through the 1973-1976 ESMR data and the 1979-1986 SMMR data (from Parkinson and Cavalieri, 1989).

is required to confirm any long-term trends and to determine the overall influences of climate, as well as the importance of atmospheric and oceanographic processes, on spatial-temporal changes in the ice cover.

\section{Studies of Open Water Areas}

Leads and polynyas are areas of open water and new ice growth within the ice cover. Smith et al. (1990) survey the properties and geographic distribution of leads and polynyas. Leads are gen-
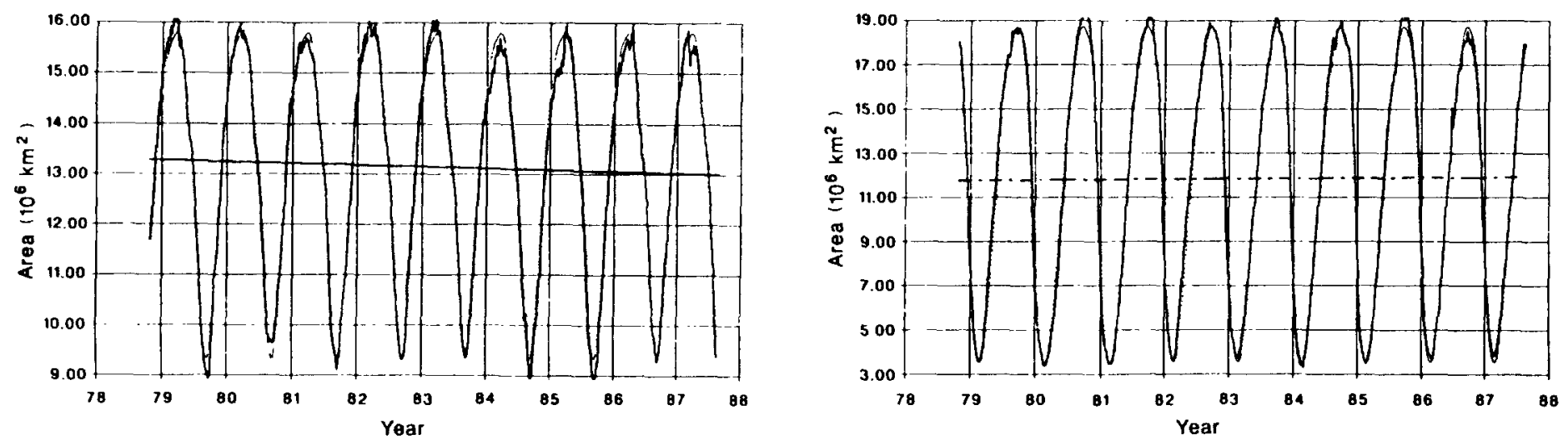

Fig. 5: Sea-ice extents (the areas enclosed by the margin of the sea-ice covers) for (left) the Arctic and (right) the Antarctic from 25 October 1978 to 20 August 1987, and their trends determined from SMMR data. The Arctic trend (-) is a 2.1\% decline over the 8.8-year interval under discussion, and is significant to the $96 \%$ confidence level. The Antarctic trend (---) in statistically insignificant (from Gloersen and Campbell. 1991). 
erally long linear features which open and close at no fixed location within the pack ice in response to wind stress (Fig. 6). Polynyas have much larger areas, a more rectangular aspect ratio than leads, and tend to recur at fixed locations (Stringer and Groves, 1991) (Fig. 7). For example, a typical Arctic lead might measure $10 \mathrm{~km}$ in length by 100 $\mathrm{m}$ in width and freeze over in the period of 1-3 days. The Weddell Sea polynya observed during 1974-1976 had a typical area of $300 \mathrm{~km} \times 1000$ $\mathrm{km}$ and was present throughout each winter season (Carsey, 1980). The fraction of open water in such polynyas can be only 1-2\% (Fig. 6), however, with $30 \%$ covered by new ice and the remainder by young ice (Steffen, 1991). Coastal polynyas are maintained by offshore winds that transport the new ice production and the pack ice away from the coast. These polynyas serve as ice factories. The second class of polynyas is maintained by the upwelling of warm oceanic water. This includes polynyas in the Weddell Sea and the Okhotsk Sea (Afultis and Martin, 1987).

Both leads and polynyas are important because they serve to transfer heat and moisture between the warm ocean and the cold atmosphere. Once a lead opens, it is immediately the source of new ice growth, which contributes a brine flux to the underlying water column and thus helps maintain the upper mixed layer of the water column. In the Arctic Ocean, the cold salty water formed within the coastal polynyas on the Alaska and Siberian continental shelves contributes to the Arctic Ocean Intermediate Water (Martin and Cavalieri, 1989). The dense water generated on the continental shelf flows down the continental slope and enters the ocean at different levels, thus contributing to the water structure. Similar polynyas form along the Antarctic coast, where they also may play a role in the maintenance of the oceanic halocline and the formation of the Antarctic Bottom Water (Cavalieri and Martin, 1985). The cooling of warm, upwelling water at the surface of the Weddell Sea polynya also contributes to this bottom-water formation.

The North Water area $\left(80,000 \mathrm{~km}^{2}\right)$, located in northern Baffin Bay between Greenland and Baffin Island, results from ice divergence and upwelling warm water (Steffen, 1985). Using the classification algorithm described by Cavalieri et al. (1984), time series of ice concentrations were derived from SMMR data for the North Water area during the winter months November to March 1978-1985 (see Fig. 8). The most striking phenomenon is the pulse-like change in ice concentration associated with ice divergence. Averaging the percentage of open-water area over the number of winter days shows a large variability in the North Water area for the 8 years. There is a range from a mean of $0.1 \%$ open water in winter $1982 / 83$ to a mean of $1.8 \%$ open water in winter $1981 / 82$.

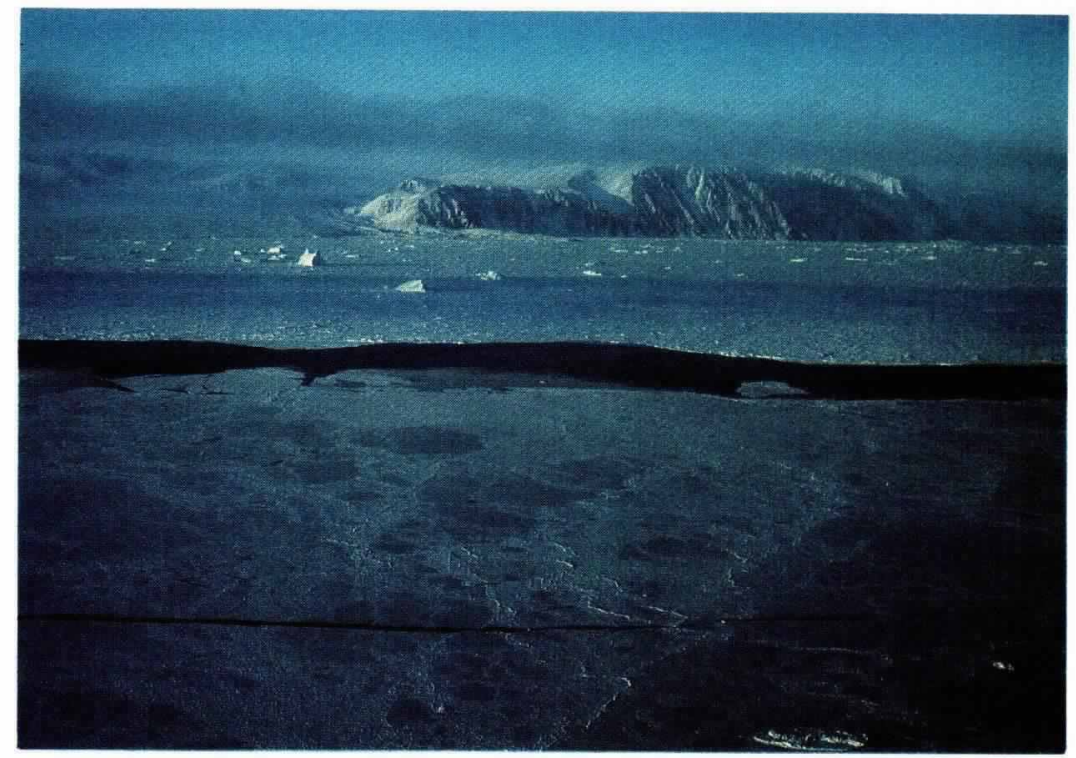

Fig. 6: In large bays or along islands the edge toward the land is commonly marked by a flaw lead at the fast ice/pack ice boundary. This lead opens and closes as the pack ice moves. For short periods, open water may exist in the lead; but more often, the lead will be covered with new ice, because of the rapid ice formation during the cold winter months. Location: Northern Baffin Bay, NW coast of Greenland at $75^{\circ} \mathrm{N}$. (Photo by Konrad Steffen).

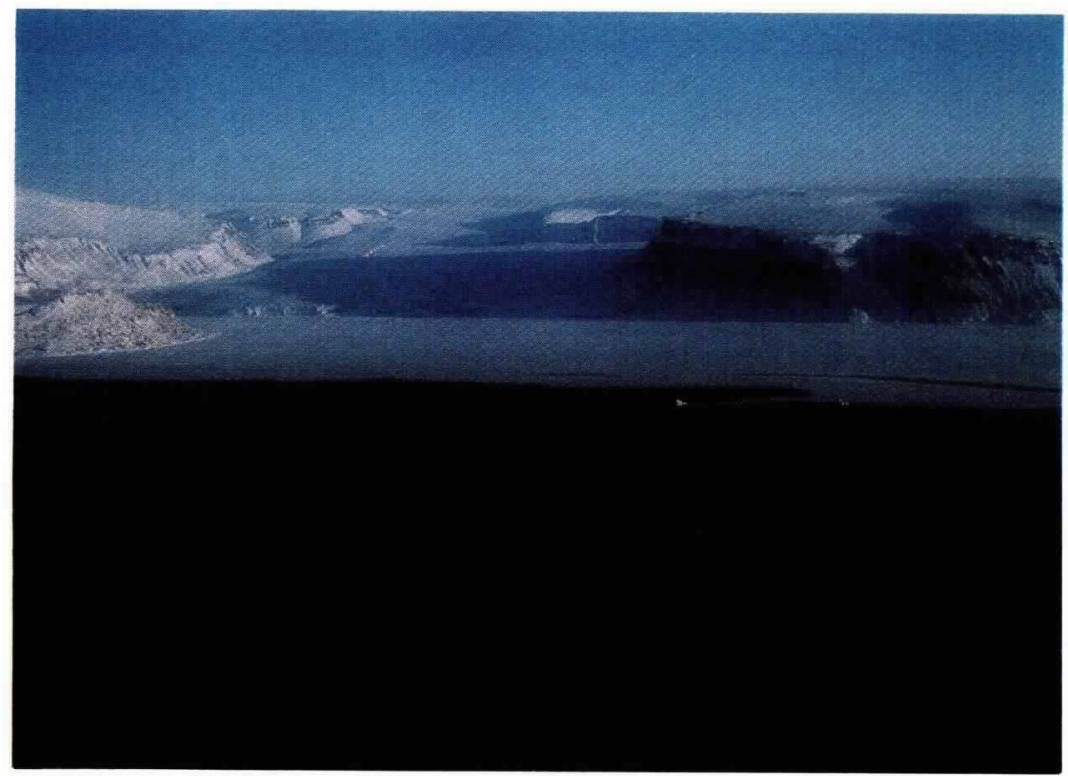

Fig. 7: Polynyas are nonlinear shaped openings enclosed in ice. They may contain brash ice and/or be covered with new ice, nilas or young ice (all ice types $<30 \mathrm{~cm}$ in thickness) throughout the winter. Polynyas may be caused by a variety of factors, the most important of which being currents, tidal fluctuations, wind, upwellings, or a combination of those forces. In the 18th century, whalers took advantage of the thin pack-ice cover usually found in polynyas to hunt. Location: Northern Baffin Bay-Smith Sound area, North Water Polynya south of Cape Alexander, Greenland at $77^{\circ} N$. (Photo by Konrad Steffen). 


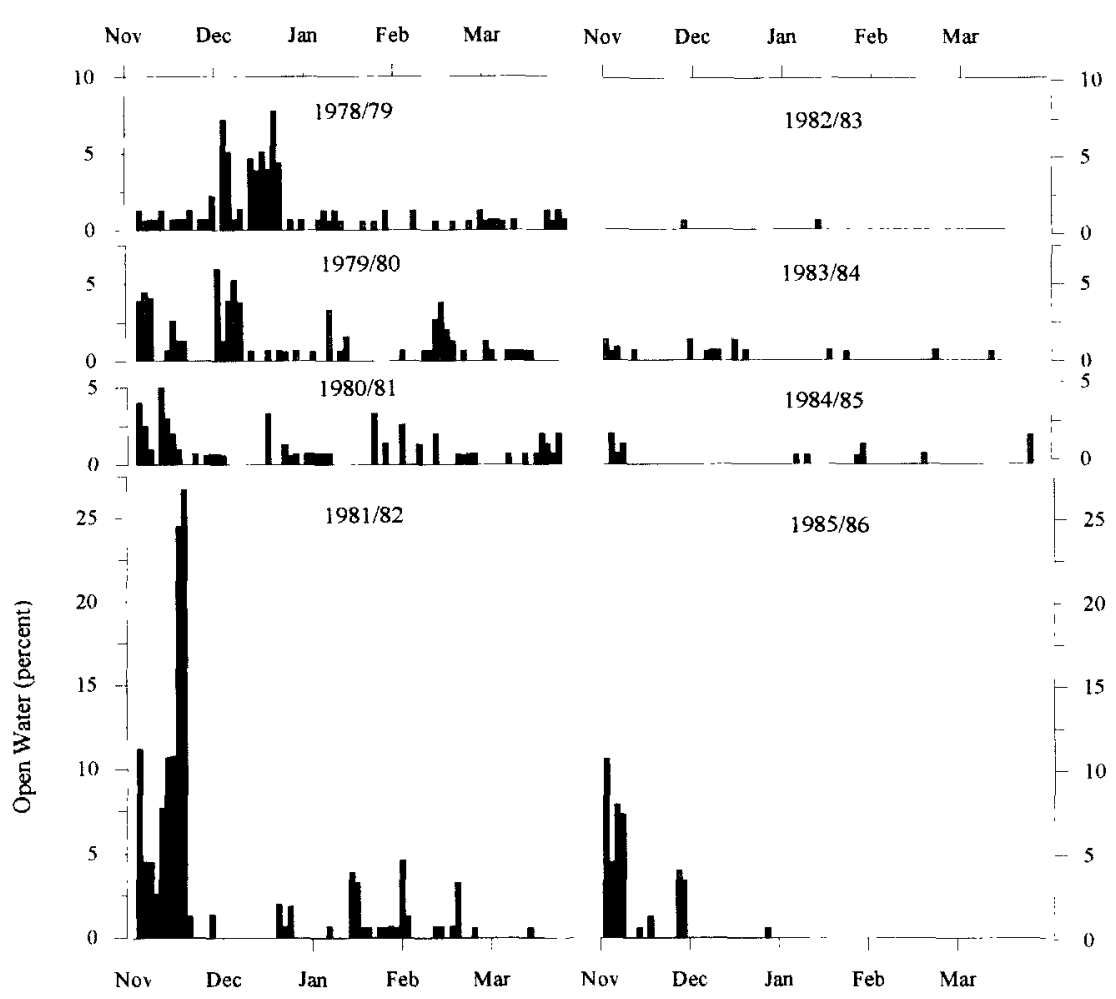

Fig. 8: Percentage of open water for the North Water polynyas area $(80,000$ $\mathrm{km}^{2}$ ) during the winter months November to March (Julian days 303-390). 1978-1985, derived from passive microwave SMMR data.

Steffen (1991) shows that when other variables such as multiyear-ice and total-ice concentration are known, different young sea-ice types can be classified based on the relation of increasing polarization ratio (18 or $37 \mathrm{GHz}$ ) with decreasing ice thickness. Estimates of energy flux density to the ice/atmosphere interface, based on the ice-type distribution derived from this classification, show there is a mean loss of $\sim 77 \mathrm{Wm}^{-2}$ for the months November to March (1978-85) over the entire North Water region (compared with winter turbulent fluxes of $\sim 500 \mathrm{Wm}^{-2}$ over the western North Atlantic Ocean). Ice formation in this polynya makes up about one-half of the energy loss, the remaining $39 \mathrm{Wm}^{-2}$ must be withdrawn from the heat content in the sea water. The application of satellite passive microwave data in young-ice typing and energy-flux estimation is limited to large homogeneous ice areas consisting of a single ice type covering one satellite footprint $(25 \times 25$ $\mathrm{km}$ at $18 \mathrm{GHz}$ ), which is a common occurrence in large polynyas such as the North Water.

It is apparent that although passive microwave data can provide estimates of total open-water proportion within a large field of view, combinations of passive microwave and higher-resolution data such as AVHRR, OLS, and Synthetic Aperture Radar (SAR) will be needed to resolve the morphology of the open-water areas. Such data combinations have been used for polar cloud de- tection (Maslanik et al.. 1989) and may prove important for the calculation of turbulent fluxes. Because the role of energy transfer is larger over small leads, the turbulent energy transfer is greater for a complex of small leads than for a smaller number of large leads of the same areal coverage. The total open-water area predicted by a sea-ice model may compare well with the corresponding area estimated from remotely sensed data, but the form of the ice openings is also important. The model physics can reproduce the large-scale divergence but cannot accurately represent local openings and closings that contribute to the total open-water area as observed in passive microwave data (e.g., Serreze et al., 1990).

\section{New Facilities and Tools For Data Distribution} and Their Analysis

Over the past 10 years the concept of data distribution has evolved from a centralized computer system supporting distribution of data on ninetrack magnetic tape (CCTs) to the practice of "publishing" compact disk-read only memory (CD-ROM)s containing specialized subsets or a complete data base. We expect that in the near future, the advent of lower-cost high-density magnetic and optical media (e.g., 8-mm cartridges, Read-Write optical disks) will permit a scientist to place the entire SMMR and SSM/I orbital data sets on a shelf for ready access. It is also becoming increasingly common to distribute software for display and extraction of data.

The most exciting emerging technology is that of the networked data center. This concept is not new-NOAA and NASA both attempted such designs during the 1980s but with limited success. With the advent of global-change research, which demands data sets that span traditional disciplinary boundaries, there is a strong impetus for closer ties between the traditional discipline- and agencyaligned data centers. Technological advances in networking hardware also reinforce the opportunities for integrative science. Fiber-optic communications circuits and improved satellite links have improved the stability of communications between data centers. Data-base management systems specifically designed for networked structures also are coming to market now.

Both NOAA and NASA, the operators of the Nation's major geophysical data centers, have started significant efforts to upgrade data centers. NASA's Earth Observation System Data and Information System (EOSDIS) is currently comprised of eight Distributed Active Archive Centers (DAAC) and several Affiliated Data Centers (ADC). Two of these, at the National Snow and Ice Data Center, University of Colorado, and at the Synthetic Aperture Radar (SAR) Facility, University of Alaska, will focus on polar and cryospheric data. It is NASA's intention to make 
these DAACs and ADCs function as a single networked system, so that the scientist can enter the system in a manner independent of where the data are physically stored and locate all available data relevant to a specific scientific question. NOAA also has started an important effort to improve access to its data holdings by establishing the Earth Sciences Data and Information Management Organization (ESDIM). NOAA also will play a major role in EOSDIS through its ADC status.

What does all this mean to sea-ice research based on passive microwave data? We suspect that advances in sea-ice algorithms utilizing passive microwave data will come through integration of passive microwave data with other satellite and in situ data sets (Barry and Maslanik, 1989) and by the use of filtering techniques to integrate observational and model-derived estimates of ice concentration (Thomas and Rothrock, 1989). Therefore, all the current efforts to provide more data directly to the scientist. and to provide more comprehensive access to other data sets and data types, with tools for their analysis, will benefit seaice research.

Future: What Are the Most Important Issues?

In regard to climate change and global warming, one of the most critical applications for passive microwave data is to help understand the role of the sea-ice cover in the formation of the intermediate and deep water. Their formation rates affect the uptake of $\mathrm{CO}_{2}$ and the other greenhouse gases, and thus may influence the rate of global warming. The regions for deep-water formation lie either within the sea-ice zone, as in Antarctica, or just at the ice edge, as in the critical region of North Atlantic Deep Water formation in the Greenland/Norwegian Sea. The sea ice plays a complex role in these regions. When they are ice covered, freezing releases salt, but inhibits heat transfer. When they are open, intense cooling occurs with no appreciable flux of salt. A methodology for understanding this process will make use of satellite data to determine the types of ice and rates of their formation in the North Atlantic, and then to combine information with numerical ocean models to predict the rates of water-mass formation.

An urgent need in climate modeling is to incorporate into process and general circulation models all aspects of ocean ice cover, namely: ice motion, ice-thickness distribution (Bourke and McLaren, 1992), the seasonal albedo cycle, brine rejection, and effects on heat transfer. The polar regions appear to be particularly sensitive to global warming, and the presence or absence of the ice cover exerts a large difference in the simulated climate (Meehl and Washington, 1990). However, with rare exceptions (e.g., Simmonds and Budd, 1990), general circulation models treat the ice cover as a continuous slab (e.g., Mitchell and Se- nior, 1989). Newer coupled ocean-atmosphere models incorporate more detailed representations of sea ice, including lead parameterization, and its snow cover (McFarlane et al., 1992). Nevertheless, passive microwave data will remain one of the principal tools available to validate simulations of ice concentration and extent.

Today, passive microwave algorithms provide valuable information for navigation and largescale sea-ice studies in polar regions. Important sea-ice parameters such as total ice concentration, ice-edge location, multiyear-ice concentration, and ice temperatures can be retrieved with an accuracy of 6 to $10 \%$ (Cavalieri et al., 1991; Steffen and Schweiger, 1991). These achievements are remarkable considering the fact that seasonal and interannual variations of the sea-ice cover on a global scale were hardly known 20 years ago.

For first-year ice, the resolution of different thickness classes with passive microwave algorithms is still an unresolved problem. For sea ice/ atmosphere interaction, the knowledge of icethickness distribution is essential, and one of the major goals for the development of new algorithms. Hopefully, this problem will be resolved in the near future with an algorithm that combines passive microwave and synthetic aperture radar (SAR) data from the European Remote Sensing Satellite-1 (ERS-1), the Japanese Earth Resources Satellite-1 (JERS-1), and the future Canadian Radar Satellite (Radarsat)). Such data combinations also will reduce the ambiguities of the present iceconcentration algorithms. Existing passive microwave algorithms could be improved further by incorporating radiative transfer models to minimize atmospheric effects and to account for surface conditions of the ice pack. Therefore, the next-generation ice algorithm most likely will be based on multi-sensor satellite data sets, including passive microwave, SAR, atmospheric sounders and possibly thermal infrared measurements. The increased availability of such data during the present decade promises exciting opportunities for sea-ice research.

Well-calibrated and documented time series of sea-ice concentration and other parameters will be necessary to address the problems discussed above. It is incumbent upon the data centers to maintain these data in stable archives. As data sets grow in size, the amount of data-center resources devoted to protecting them and transferring them onto new media must increase. The more basic issue of having media that are stable over a time-scale of more than 10 years remains to be solved, despite ongoing advances in technology.

\section{Acknowledgement}

Our collective research activities have been supported by the Polar Oceans Program of NASA.
... the next-

generation ice

algorithm . . . will be

based on multi-sensor

satellite data sets . . . 
References

Alfultis, M.A. and S. Martin, 1987: Satellite passive microwave studies of the Sea of Okhotsk ice cover and its relation to oceanic processes, 1978-1982. J. Geophys. Res., 92, 13013-13028.

Barry, R.G., 1991: Cryospheric products from the DMSP SSM/l: status and research applications. Paleogeogr., Palaeoclimatol., Palaeoecol., Global Planet. Change, 90, 231234.

and J. Maslanik, 1989: Arctic Sea ice characteristics and associated atmosphere-ice interactions in summer inferred from SMMR data and drifting buoys: 19791984. Geojournal, 18(1), 35-44.

Bourke, R.H. and A.S. McLaren, 1992: Contour mapping of Arctic Basin ice draft and roughness parameters. $J$. Geophys. Res., 97(C11), 17715-17728.

Carsey. F.D., 1980: Microwave observation of the Weddell polynya. Mon. Wea. Rev., 108, 2032-2044. (ed.) 1993: Microwave Remote Sensing of Sea Ice. American Geophysical Union, Washington, DC, Geophys. Monogr. 68, $462 \mathrm{pp}$.

Cavalieri, D.J., P. Gloerson and W.J. Campbell, 1984: Determination of sea ice parameters with Nimbus-7 SMMR. J. Geophys. Res., 89, 5355-5363.

and S. Martin, 1985: A passive microwave study of polynyas along the Antarctic Wilkes Land coast. In: Oceanology of the Antarctic Continental Shelf Antarctic Res. Ser. 43, S.S. Jacobs, ed. American Geophysical Union, Washington, D.C., 227-256.

and C.L. Parkinson, 1981: Large-scale variations in observed Antarctic sea ice extent and associated atmospheric circulation. Mon. Wea. Rev., 109, 23232336.

and C.L. Parkinson, 1987: On the relationship between atmospheric circulation and the fluctuations in the sea ice extents of the Bering and Okhotsk seas. $J$. Geophys. Res., 92, 7141-7162.

, J.R. Crawford, M.R. Drinkwater, D.T. Eppler, L.D. Farmer, R.R. Jentz, and C.C. Wackerman, 1991: Aircraft active and passive microwave validation of sea ice concentration from the DMSP SSM/I. J. Geophys. Res., 96, 21989-22008.

Chahine, M., D.J. McCleese, P.W. Rosenkranz, and D.H. Staelin, 1983: Interaction mechanisms with the atmosphere. In: Manual of Remote Sensing, Vol. 1, R.N. Colwell, ed. Amer. Soc. Photogramm, Falls Church. VA. Vol. 1, 165-230.

Comiso, J.C. and C.W. Sullivan, 1986: Satellite microwave and in situ observations of the Weddell Sea ice cover and its marginal ice zone. J. Geophys. Res., 91(C8), 9663-9681.

Gloersen, P. and W.J. Campbell, 1988: Variations in the Arctic, Antarctic, and global sea ice covers during 1978-1987 as observed with the Nimbus-7 SMMR. J. Geophys. Res., 3(C9), 10666-10674.

and W.J. Campbell, 1991: Recent variations in Arctic and Antarctic sea-ice covers. Nature, 352, 33-66.

Gordon, A.L., 1981: Seasonality of Southern Ocean sea ice. $J$. Geophys. Res., 86(C5), 1124-1131.

Martin, S. and D.J. Cavalieri, 1989: Contributions of the Siberian shelf polynyas to the Arctic Ocean intermediate and deep water. J. Geophys. Res., 94, 12725-12738.

Maslanik, J.A., 1992: Effects of weather on the retrieval of sea ice concentration and type from passive microwave data. Int. J. Rem. Sens., 3(1), 37-54.

, J. Key and R.G. Barry, 1989: Merging AVHRR and SMMR data for remote sensing of ice and cloud in polar regions. Int. J. Rem. Sens., IO(10), 1691-1696.

McFarlane, N.A.. G.J. Boer, J.P. Blanchet and V. Lazare, 1992: The Canadian Climate Centre second-general circulation model and its equilibrium climate. $J$. Climate. 5 . 1013-1044.

Meehl, G.A., and W.M. Washington, 1990: $\mathrm{CO}_{2}$ climate sensitivity and snow-sea ice-albedo parameterization in an atmospheric GCM coupled to a mixed-layer ocean model. Climatic Change, 16, 283-306.

Mitchell, J.F.B. and C.A. Senior, 1989: The Antarctic winter: simulations with climatological and reduced ice extents. Quart. J. Roy. Meteor. Soc., 115, 225-246.

Parkinson, C.L. and D.J. Cavalieri, 1989: Arctic Sea Ice 19731987: Seasonal, regional and international variability. J. Geophys. Res., 94, 14499-14523.

, J.C. Comiso, H.J. Zwally, D.J. Cavalieri, P. Gloersen and W.J. Campbell, 1987: Arctic Sea Ice, 1973-1976: Satellite Passive-Microwave Observations. NASA, Washington DC, 296 pp.

Serreze, M.C., J.A. Maslanik, R. Preller and R.G. Barry, 1990: Sea ice concentration in the Canada Basin during 1988: Comparisons with other years and evidence of multiple forcing mechanisms. J. Geophys. Res., 95(CI2), 2225322267.

Simmonds, I. and W.F. Budd, 1990: A simple parameterization of ice leads in a general circulation model and the sensitivity of climate to change in Antarctic ice concentration. Ann. Glaciol., 14, 266-269.

Smith, S.D., R.D. Muench and C.H. Pease, 1990: Polynyas and leads: an overview of physical processes and environment. J. Geophys. Res., 95, 9461-9479.

Steffen, K., 1985: Warm water cells in the North Water, northern Baffin Bay during winter. J. Geophys. Res., 90(C5), 9129-9136.

, 1991: Energy density estimation over sea ice based on satellite passive microwave measurements. Ann. Glaciol., 15, 178-183.

and A. Schweiger, 1991: NASA team algorithm for sea ice concentration retrieval from Defense Meteorological Satellite Program Special Sensor Microwave Imager: comparison with Landsat satellite imagery. $J$. Geophys. Res., 96(C12), 21971-21987.

Stringer, W.T. and J.E. Groves. 1991: Location and areal extent of polynyas in the Bering and Chukchi seas. Arctic, 44, Supp. 1, 164-171.

Thomas, D.R. and D.A. Rothrock, 1989: Blending sequential Scanning Miltichannel Microwave Radiometer and buoy data into a sea ice model. J. Geophys. Res., 94(C8), 10907-10920.

Thomas, R.H., 1991: Polar Research from Satellites. Joint Oceanographic Institutions, Inc., Washington, DC, 91 pp.

Waters, J.W, 1976: Absorption and emission by atmospheric gases. In: Methods in Experimental Physics, Vol. 12, Part B, Astrophysics, Radio Telescopes, M.L. Meeks, ed., Academic Press, New York. 142-176.

Zwally, H.J., J.C. Comiso, C.L. Parkinson, W.J. Campbell, F.D. Carsey and P. Gloersen, 1983: Antarctic Sea Ice, 1973-1976: Satellite Passive-Microwave Observations. NASA, SP-459, Washington, DC, 206 pp. $\square$ 